\title{
Erythropoietin dosing in children with chronic kidney disease: based on body size or on hemoglobin deficit?
}

\author{
Ruediger E. Port • Otto Mehls
}

Published online: 15 May 2009

(C) IPNA 2009

Erratum to: Pediatric Nephrology

DOI 10.1007/s00467-008-0955-2

It has come to our attention that

1. All given levels for hemoglobin should have the unit $\mathrm{g} / \mathrm{dl}$ and not $\mathrm{g} / \mathrm{l}$.

2. The formula for the expected increase of hemoglobin from a pretreatment level to a desired steady state level misses a divisor.

The correct formula is as follows:

$\mathrm{d} \approx 2400 \mathrm{IU} / \sqrt{\frac{9.6}{H b_{s s}-H b_{0}}-1}$

The online version of the original article can be found at http://dx.doi. oeg/10.1007/s00467-008-0955-2.

R. E. Port

Genentech Inc.,

South San Francisco, CA, USA

O. Mehls $(\square)$

Division of Pediatric Nephrology,

University Hospital for Children and Adolescents,

Heidelberg, Germany

e-mail: otto.mehls@med.uni-heidelberg.de 